\title{
PENGARUH KEPEMIMPINAN DAN MOTIVASI KERJA \\ TERHADAP SEMANGAT KERJA PEGAWAI PADA \\ PERUSAHAAN DAERAH AIR MINUM (PDAM) SAUMLAKI \\ KABUPATEN MALUKU TENGGARA BARAT
}

ISSN : 2656-3363-Vol.1. No.2 -2019

BY :

( ANDREAS J. WATKAAT)

DOSEN STIE-SAUMLAKI

\begin{abstract}
ABSTRAK
Dalam suatu organisasi yang baik terdapat sumberdaya manusia yang baik pula. setiap organisasi memerlukan sumber daya yang baik untuk mencapai tujuanya. Sumber daya yang ada pada suatu organisasi merupakan sumber energi, tenaga, kekuatan yang diperlukan untuk menciptakan aktivitas ataupun kegiatan yang diharapkan nantinya bisa mencapai tujuan organisasi. Sumber daya manusia merupakan asset organisasi yang paling penting dalam menggerakan sumber daya lainnya untuk mencapai tujuan organisasis. Dengan demikian, tanpa sumber daya manusia sumberdaya lainnya tidak dapat digunakan dengan baik dan maksimal. Untuk itu sumber daya manusia sebagai asset organisasi yang sangat fital ini perlu dilakukan pengelolaan dengan baik. Agar proses perencanaan, pengorganisasian, pengarahan, dan pengawasan yang melibatkan Pemimpin serta bawahan sehingga bisa menciptakan motivasi yang baik guna memacu semangat kerja pimpinan maupun bawahan agar bisa mencapai tujuan organisasi yang telah ditetapkan.

Tujuan Penilitian ini adalah untuk mengetahui pengaruh kepemimpinan dan motivasi kerja terhadap semangat kerja pegawai pada Perusahaan Daerah Air Minum (PDAM) Saumlaki Kabupaten Maluku Tenggara Barat. Penelitian ini mengunakan metode Non - probability sampling dengan Kuesioner sebagai alat pengumpulan data. Populasi dalam penelitiian ini Seluruh pegawai (PDAM) $\begin{array}{llll}\text { Saumlaki Kabupaten } & \text { Maluku }\end{array}$
\end{abstract}


Hasil Penelitian ini menunjukan bahwa : Secara Parsil maupun secara Simultan kedua-duanya sama - sama menunjukan bahwa adanya Pengaruh Kepemimpinan Dan Motivasi Kerja Terhadap Semangat Kerja Pegawai.

\section{Kata Kunci : Kepemimpinan, Motivas Kerja dan Semangat Kerja Pegawai PENDAHULUAN}

Dalam mencapai tujuan organisasi, setiap organisasi memerlukan sumber daya untuk mencapai tujuanya. Sumber daya merupakan sumber energi, tenaga, kekuatan yang diperlukan untuk menciptakan aktivitas ataupun kegiatan. Sumber daya itu antara lain sumber daya alam, sumber daya finansial, sumber daya ilmu pengetahuan dan teknologi, serta sumber daya manusia. Diantara sumber daya tersebut, sumber daya yang terpenting ialah sumber daya manusia (Wirawan, 2009). Sumber daya manusia dianggap penting karena dapat mempengaruhi efisiensi dan efektifitas organisasi, serta merupakan pengeluaran pokok organisasi dalam menjalankan kegiatannya (Simamora, 2006).

Sumber daya manusia yaitu sumber daya yang digunakan untuk menggerakkan, dan mensinergikan sumber daya lainnya untuk mencapai tujuan organisasi (Wirawan, 2009). Sejalan dengan itu Simamora (2006) mendefinisikan bahwa sumber daya manusia merupakan asset organisasi yang paling penting, dan membuat sumber daya organisasi lainnya menjadi bekerja. Dengan demikian, tanpa sumber daya manusia sumberdaya lainnya akan menganggur dan kurang bermanfaat dalam mencapai tujuan organisasi. Untuk itu sumber daya manusia sebagai asset organisasi perlu dilakukan pengelolaan (manajemen) dengan baik. Menurut Stoner (1996) manajemen merupakan proses perencanaan, pengorganisasian, pengarahan, dan pengawasan usaha-usaha para anggota organisasi, serta penggunaan sumber daya manusia, dan sumberdaya lainnya agar tercapai tujuan organisasi yang telah ditetapkan.

Manajemen sumber daya manusia (msdm) sendiri adalah serangkaian fungsi manajemen (perencanaan, pengorganisasian, pengarahan, dan pengendalian) yang dijadikan dasar dilaksanakannya fungsi msdm (pengadaan, pengembangan, kompensasi, pengintegrasian, pemeliharaan, dan pemberhentian pegawai), dengan 
maksud terwujudnya tujuan organisasi, individu pegawai, dan masyarakat (Flippo, 1984). Adapun tugas msdm menurut Gibson, et al (1995) yaitu berkisar pada upaya mengelola unsur manusia dengan potensi yang dimiliki sehingga dapat diperoleh sumber daya manusia yang puas (satisfied), dan memuaskan (satisfactory) bagi organisasi.

Dalam mewujudkan keberhasilan suatu organisasi dibutuhkan seorang pemimpin, yang memiliki motivasi yang tinggi serta mempunyai semangat kerja yang tinggi pula. (Suranta, 2002). Kepemimpinan ialah kemampuan dan keterampilan seseorang atau individu yang menduduki jabatan sebagai pimpinan satuan kerja, untuk mempengaruhi perilaku orang lain terutama bawahannya, untuk berfikir dan bertindak sedemikian rupa, sehingga melalui perilaku yang positif tersebut dapat memberikan sumbangsih nyata dalam pencapaian tujuan organisasi (Siagian, 2002). Menurut Sjafri, et.al. (2007 : 113), motivasi merupakan dorongan yang membuat karyawan melakukan sesuatu dengan cara dan untuk mencapai tujuan tertentu. Alex S. Nitisemito (1990:84) mendefinisikan semangat kerja adalah melakukan pekerjaan secara lebih giat sehingga dengan demikian pekerjaan dapat diharapkan lebih cepat dan lebih baik. Berbeda pula Moekijat (1981 : 130), semangat atau moril kerja yaitu kemampuan sekelompok orang untuk bekerja sama dengan giat dan konsekuen dalam mengejar tujuan bersama.

Dengan demikian dapat disimpulkan bahwa pemimpin yang mempunyai motivasi yang tinggi serta memiliki semangat kerja tinggi akan mampu mempengaruhi dan menggerakkan orang yang dipimpinya agar mau bekerja sama dalam mencapai tujuan perusahaan.

Dengan demikian untuk menjamin terlaksanya seluruh tutgas-tugas pada kantor PDAM Saumlaki. sesuai dengan apa yang telah direncanakan oleh organisasi maka diperlukan semangat kerja pegawai yang tinggi. Hal ini dapat dilakukan denga cara menemukan pemimpin yang handal, memiliki motivasi yang tinggi, serta memiliki semangat kerja yang baik dan mampu menjadi teladan bagi orang yang dipimpinya. 


\section{KERANGKA PEMIKIRAN}

\section{Gambar 2.3}

Kerangka Pemikiran

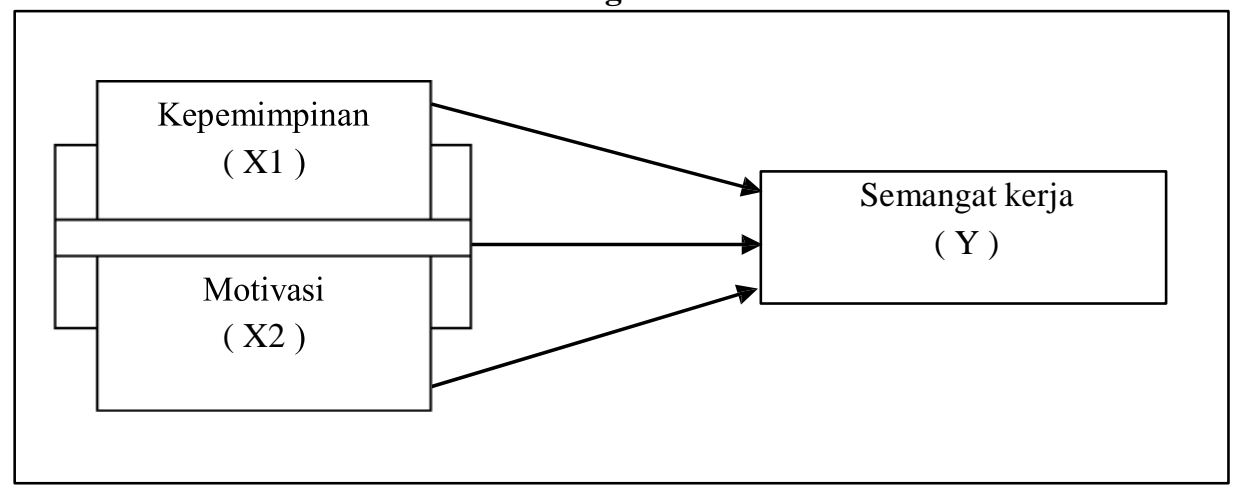

Dari gambar kerangka pemikiran di atas dapat di uraikan bahwa :

1. Kepemimpinan berpengaruh secara parsial terhadap Semangat kerja pegawai.

2. Motivasi berpengaruh secara parsial terhadap Semangat kerja pegawai.

3. Kepemimpinan dan Motivasi berpengaruh secara simultan terhadap Semangat kerja pegawai.

Semangat kerja pegawai pada Perusahaan Daerah Air Minum (PDAM) sangat di pengaruhi oleh kepemimpinan dan motivasi yang dialkukan oleh pemimpin itu sendiri. Dengan kata lain bagus atau tidaknya semangat kerja akan meningkat sangat tergantung pada kedua variabel ini yaitu kepemimpinan dan motivasi.

Berdasarkan latar belakang, rumusan masalah, tujuan penelitian, manfaat penelitian dan penelitian terdahulu, maka peneliti berpendapat bahwa semangat kerja adalah sikap mental individu atau kelompok di dalamnya, yang terdapat dalam satu organisasi yang menunjukkan rasa kegairahan di dalam melaksanakan tugas pekerjaan dan mendorong mereka untuk bekerja secara lebih baik dan produktif Edwin B. Flippo (Kerlinger, et.al, 1987 : 157) dan hal ini sangatlah ditentukan oleh kepemimpinan atau pimpinan dan motivasi yang diberikan kepada pegawai

Kepemimpinan + Motivasi yang baik = peningkatan semangat kerja gawai 


\section{POPULASI DAN SAMPEL}

Sugiyono (2002 : 57) memberikan pengertian bahwa populasi adalah wilayah generalisasi yang terdiri dari objek atau subjek yang menjadi kuantitas dan karateristik tertentu yang di tetapkan oleh peneliti untuk di pelajari dan kemudian di tarik kesimpulannya. Jadi dapat di katakana bahwa populasi merupakan total keseluruhan pegawai di mana penelitian ini di lakukan yaitu total keseluruhan pegawai pada Perusahaan Daerah Air Minum (PDAM) sebanyak 43 orang

Sugiyono (1997 : 57) memberikan pengertian bahwa sampel adalah sebagian dari jumlah dan karakteristik yang di miliki oleh populasi. Populsi sebanyak 43 orang Jadi dapat di katakana bahwa sampel adalah suatu himpunan bagian dari populasi yang di jadikan sampel yaitu 34 orang.

Teknik pengambilan sampel dengan menggunakan rumus :

$$
\begin{aligned}
n=\frac{N}{N \cdot d^{2}+1} \\
\text { Dimana }: \mathrm{n}=\text { Jumlah sampel } \\
\mathrm{N}=\text { Jumlah populasi } \\
\mathrm{d}^{2}=\text { Presisi yang ditentukan }
\end{aligned}
$$

Penelitian ini menggunakan teknik sampling Non - probability sampling.

Sugiyono (2010 : 120) mengatakan Non - probability sampling adalah teknik sampling yang tidak memberikan kesempatan atau peluang pada setiap anggota populasi untuk di jadikan sampel.

\section{METODE ANALISISN DATA}

Reliabilitas menunjukan pada suatu pengertian bahwa. suatu instrumen cukup dapat dipercaya untuk dapat digunakan sebagai alat pengumpul data karena instrumen tersebut sudah baik. Instrumen yang reliabel adalah instrumen yang bila 
digunakan beberapa kali untuk mengukur obyek yang sama akan menghasilkan data yang sama pula (Sugiyono, 1999 : 109).

Dapat dirumuskan sebagai berikut:

$$
R x y=\left(\frac{k}{1-k-1}\right)\left(\frac{\Sigma S i}{S t}\right)
$$

Keterangan :

$$
\begin{aligned}
& \mathrm{R}=\text { Nilai Reliabilitas } \\
& \sum \mathrm{Si}=\text { Jumlah varian skor tiap-tiap item } \\
& \mathrm{St}=\text { varian total } \\
& \mathrm{K}=\text { Jumlah item }
\end{aligned}
$$

Untuk mengukur instrumen penelitian digunaken skla likert yaitu skala yang digunakan untuk mengukur variabel penelitian seperti sikap, pendapat, dan presepsi sosial seseorang atau sekelompok orang (M. Iqbal Hasan, 2004 : 72) .dengan 5 poin scale.

Untuk mengukur masing-masing variable Kepemimpinan (Xl) Motivasi (X2), maka digunakan skala Iikert yang diasumsikan mempunyai interval yang sama, dalam melakukan uji valliditas instrumen, peneliti menggunakan program SPSS 16,0 dengan level signifikan yang digunakan adalah 5\%. Jika $\mathrm{r}_{\text {hitung }}>\mathrm{r}_{\text {table }}$ maka pernyataan tersebut valid.

Untuk menguji apakah masing-masing item pertanyaan valid atau tidak, dapat dilihat pada tampilan output dari Cronbach Alpha pada kolom Pearcion Correlationn, dan membandingkan dengan hasil dari perhitungan $r_{\text {tabel. }}$. Dalam penelitian ini, analisis validitas menggunakan kuesioner sebanyak 30. Dari hasil pengolahan uji validitas sebanyak 30 responden dan dengan ketentuan $\mathrm{n}-2$, (30$2=28$ ), maka diketahui $r_{\text {tabel }}=0,28$. Jika hasil yang diperoleh:

$$
\begin{aligned}
& r \text { hitung }>r \text { tabel }(0.28) \rightarrow \text { valid } \\
& r \text { hitung }<\mathrm{r} \text { tabel }(0.28) \rightarrow \text { tidak valid. }
\end{aligned}
$$

Uji validitas digunakan untuk mengetahui kecermatan suatu test dalam melakukan fungsi ukur. Dalam pengujian ini digunakan Person Product Moment (Umar, 1999 : 195).

Dengan Rumus sebagai berikut: 


$$
r=\frac{n\left(\sum X Y\right)-\left(\sum X\right)\left(\sum Y\right)}{\sqrt{\left\{n \sum X^{2}-\left(\sum X^{2}\right)\right\}\left\{n \sum X^{2}-\left(\sum Y\right)^{2}\right\}}}
$$

Keterangan:

$\mathbf{r}$ : Koefisien korelasi setiap pertanyaan atau item

$\mathbf{x}$ : Skor atau nilai dari setiap pertanyaan atau item

$\mathbf{y}$ : Skor atau tabel nilai dari setiap pertanyaan atau item

n : Jumlah sampel ( responden)

Reliabilitas adalah sesuatu instrumen cukup dapat dipercaya untuk digunakan sebagai alat pengumpul data karena instrumen tersebut sudah baik (Ghozali, 2006 : 41). Pada penelitian ini untuk mencari reliabilitas instrumen menggunakan rumus alpha $\boldsymbol{\alpha}$, karena instrumen dalam penelitian ini berbentuk angket atau daftar pertanyaan yang skornya merupakan rentangan antara 1-5 dan uji validitas menggunakan item total, dimana untuk mencari reliabilitas instrumen yang skornya bukan 1 dan 0 , misalnya angket atau soal bentuk uraian maka menggunakan rumus alpha $\boldsymbol{\alpha}$.

Reliabilitas adalah sejauh mana hasil suatu pengukuran dapat dipercaya, maksudnya apabila dalam beberapa pelaksanaan pengukuran terhadap kelompok yang sama diperoleh hasil yang relatif sama (Syaifuddin Azwar, 2000 : 3). Dalam penelitian ini, uji reliabilitas dilakukan dengan menggunakan teknik Formula Alpha Cronbach dan dengan menggunakan program SPSS 16.0.

Rumus :

$$
\boldsymbol{\alpha}=\frac{k}{k} 11 \frac{S^{2} j}{S^{2} x}
$$

Keterangan :

$$
\begin{aligned}
& \alpha=\text { koefisien reliabilitas alpha } \\
& \mathrm{k}=\text { jumlah item } \\
& \mathrm{Sj}=\text { varians responden untuk item }
\end{aligned}
$$




$$
\mathrm{Sx}=\text { jumlah varians skor total }
$$

Indikator pengukuran reliabilitas menurut (Sekaran 2000 : 312) yang membagi tingkatan reliabilitas dengan kriteria sebagai berikut :

Jika alpha atau $r$ hitung :

1. $0,8-1,0=$ Reliabilitas baik

2. 0,6-0,799= Reliabilitas diterima

3. $<0,6=$ Reliabilitas kurang baik

Variabel dikatakan reliabel jika memberikan nilai Cronbach Alpha > 0,60 (Nunnaly,1967 didalam Imam Ghozali, 2002 : 42) atau dengan kata lain :

$$
\begin{aligned}
& r \text { hitung }>r \text { tabel }(0.60) \rightarrow \text { reliabel } \\
& r \text { hitung }<\mathrm{r} \text { tabel }(0.60) \rightarrow \text { tidak reliabel }
\end{aligned}
$$

Untuk menguji apakah suatu variabel dikatakan reliabel atau tidak, dapat dilihat pada tampilan output dari Reliability statistics pada kolom Cronbach's Alpha dan membandingkan dengan hasil dari perhitungan $\mathrm{r}_{\text {tabel }}$ (limit of Coeficient Cronbach's Alpha)

\section{Uji Regresi Linear Berganda}

Metode analisis data yang digunakan dalam penelitian ini adalah Regresi berganda. Analisis regresi linier berganda digunakan untuk mengetahui pengaruh variabel bebas terhadap variabel terikat atas perubahan dari setiap peningkatan atau penurunan variabel bebas yang akan mempengaruhi variabel terikat. (Supranto,2001:236) :

$$
\mathrm{Y}=\mathrm{a}+\mathrm{b} 1 \mathrm{X} 1+\mathrm{b} 2 \mathrm{X} 2+\mathrm{e}
$$

Dimana :

$\mathrm{Y}=$ Semangat Kerja

b1 = Koefisien regresi variabel X1 (kepemimpinan)

b2 = Koefisien regresi variabel X2 (motivasi)

$\mathrm{X} 1$ = Kepemimpinan

$\mathrm{X} 2$ = Motivasi

$\mathrm{e}=$ error / variabel pengganggu

$\mathrm{a}=$ konstanta 


\section{PEMBAHASAN}

Dalam penelitian ini, peneliti menggunakan uji validitas untuk mengetahui sah tidaknya suatu instrumen yang digunakan dalam pengumpulan data. Sebuah instrumen dikatakan valid, jika mampu mengukur apa yang diinginkan dan mengungkapkan data dari variabel yang diteliti secara tepat (Ghozali,2006). Apabila korelasi antara masing-masing indikator terhadap total skor menunjukkan hasil > 2,048 maka dapat disimpulkan bahwa masing-masing indikator pernyataan adalah valid (Sugiyono, 2005)

Tabel 4.10

Hasil uji validitas Variabel Peneltian

\begin{tabular}{|c|c|c|c|c|}
\hline Variabel & No Item & r hitung & r tabel & Keterangan \\
\hline \multirow{3}{*}{ Kepemimpinan } & 1 & 0,342 & 2,048 & Valid \\
& 2 & 0,722 & 2,048 & Valid \\
& 3 & 0,667 & 2,048 & Valid \\
$\left(\mathrm{X}_{1}\right)$ & 5 & 0,722 & 2,048 & Valid \\
& 6 & 0,492 & 2,048 & Valid \\
& 7 & 0,243 & 2,048 & Valid \\
& 8 & 0,356 & 2,048 & Valid \\
& 1 & 0,584 & 2,048 & Valid \\
\hline \multirow{3}{*}{ Motivasi } & 2 & 0,659 & 2,048 & Valid \\
& 3 & 0,659 & 2,048 & Valid \\
(X) & 4 & 0,303 & 2,048 & Valid \\
& 5 & 0,367 & 2,048 & Valid \\
& 1 & 0,511 & 2,048 & Valid \\
\hline \multirow{3}{*}{ Semangat Kerja } & 2 & 0,741 & 2,048 & Valid \\
Pegawai & 3 & 0,566 & 2,048 & Valid \\
& 4 & 0,382 & 2,048 & Valid \\
& 5 & 0,071 & 2,048 & Valid \\
& 6 & 0,615 & 2,048 & Valid \\
(Y) & 7 & 0,479 & 2,048 & Valid \\
& 8 & 0,499 & 2,048 & Valid \\
& 9 & 0,407 & 2,048 & Valid \\
& $5 a l i d$ \\
\hline
\end{tabular}

Sumber : diolah berdasarkan kuisioner yang diedarkan Tahun 2015

Dari tabel 4.10 di atas dapat dilihat bahwa semua item pertanyaan untuk tiap variabel menunjukan bahwa nilai koefisien korelasi untuk tiap item menunjukan nilai koefisien > 2,048. Nilai ini menunjukan bahwa tiap item pertanyaan yang ada pada variabel penelitian adalah valid. Yang mana dapat di lihat dalam pengolahan IBM SPSS 16.0 Dengan demikian butir-butir pertanyaan dapat dipakai untuk analisis selanjutnya. 
Suatu kuisioner dikatakan reliabel atau handal jika jawaban seseorang terhadap pertanyaan adalah konsisten dari atau stabil dari waktu ke waktu. Formula statistika yang digunakan untuk mengukur reliabilitas adalah uji statistik Cronbach Alpha $(\alpha)$.

Suatu konstruk atau variabel dikatakan reliabel jika memberikan nilai Cronbach Alpha > 0,60 (Ghozali, 2006). Pengujian reliabilitas dilakukan dengan bantuan program SPSS (Statistical Package For Social Science) versi 16. Berikut Hasil uji reliabilitas variabel-variabel penelitian dapat dilihat pada tabel 4.11 di bawah ini :

Tabel 4.11

Hasil Uji Reliabilitas

\begin{tabular}{|c|c|c|c|c|c|}
\hline NO & Variabel & $\begin{array}{c}\text { Cronbachs } \\
\text { Alpha }\end{array}$ & $\begin{array}{c}\text { n of } \\
\text { items }\end{array}$ & $\begin{array}{c}\text { Limit of } \\
\text { Coecient } \\
\text { Cronbach } \\
\text { Alpha }\end{array}$ & Keterangan \\
\hline 1 & Kepemimpinan (X1) & 0.757 & 9 & 0,60 & Reliabel \\
\hline 2 & Motivasi (X2) & 0.603 & 6 & 0,60 & Reliabel \\
\hline 3 & Semangat Kerja (Y) & 0.716 & 9 & 0,60 & Reliabel \\
\hline
\end{tabular}

Sumber : diolah berdasarkan kuisioner yang diedarkan Tahun 2015

Dari tabel 4.11 di atas menunjukan bahwa alat ukur yang dipakai dalam penelitian ini adalah reliabel, dimana nilai Cronbach Alpha untuk masing-masing variabel lebih besar dari 0.60 yang mana dari pengolahan data SPSS masing masing item dinyatakan Valid sehingga dapat dipakai untuk pengolahan data selanjutnya.

a. Pengaruh Kepemimpinan, dan Motivasi Terhadap Semangat Kerja Pegawai

b. Untuk menguji ada tidaknya pengaru Kepemimpinan, dan Motivasi Terhadap Semangat Kerja Pegawai digunakan analisis regresi linier berganda. Ketentuan analisis regresi berganda yang 
digunakan dalam penelitian ini adalah sebagai berikut : Pengaruh Kepemimpinan, dan Motivasi secara signifikan berpengaruh terhadap Semangat Kerja Pegawai

1. Menentukan Ho dan Ha

Ho: $\beta_{1}=\beta_{2}=0$

Kepemimpinan, dan Motivasi secara simultan tidak berpengaruh signifikan terhadap Semangat Kerja Pegawai.

$H a: \beta_{1} \neq \beta_{2} \neq 0$

Kepemimpinan, dan Motivasi secara simultan berpengaruh signifikan terhadap Semangat Kerja Pegawai.

2. Penerimaan Ho dan Ha:

$$
F_{\text {hitung }}<F_{\text {tabel }} ; \text { probabilitas }(p)>0,05
$$

Ho diterima bila

$$
F_{\text {hitung }} \geq F_{\text {tabol }} ; \text { probabilitas }(p) \leq 0,05
$$

Ha diterima bila

Berdasarkan ketentuan analisis regresi linier berganda diatas maka dapat kita lihat pada tabel 4.12 sebagai hasil analisis regresi linier berganda yang telah dilakukan sebagai berikut:

Tabel 4.12

\begin{tabular}{|c|c|c|c|c|c|c|}
\hline \multicolumn{7}{|c|}{ Coefficients $^{a}$} \\
\hline \multirow{2}{*}{\multicolumn{2}{|c|}{ Model }} & \multicolumn{2}{|c|}{$\begin{array}{l}\text { Unstandardized } \\
\text { Coefficients }\end{array}$} & \multirow{2}{*}{$\begin{array}{c}\text { Standardized } \\
\text { Coefficients } \\
\text { Beta }\end{array}$} & \multirow[t]{2}{*}{$\mathrm{T}$} & \multirow[t]{2}{*}{ Sig. } \\
\hline & & $\mathrm{B}$ & Std. Error & & & \\
\hline \multirow[t]{3}{*}{1} & |(Constant) & -33.434 & 17.963 & - & -1.861 & .074 \\
\hline & $\begin{array}{c}\text { X1 ( } \\
\text { Kepemimpinan) }\end{array}$ & 1.087 & .143 & .754 & 7.587 & .000 \\
\hline & $\begin{array}{c}\mathrm{X} 2 \\
\text { ( Motivasi ) }\end{array}$ & 1.463 & .612 & .238 & 2.392 & .024 \\
\hline \multicolumn{2}{|c|}{ Ajd. $R$ Square } & \multicolumn{5}{|l|}{0,848} \\
\hline \multicolumn{2}{|c|}{$F_{\text {hitumg }}$} & \multicolumn{5}{|l|}{81,671} \\
\hline \multicolumn{2}{|c|}{ Probabilitas } & \multicolumn{5}{|l|}{0,000} \\
\hline
\end{tabular}

Pengaruh kepemimpinan, dan motivasi terhadap semangat kerja Pegawai 


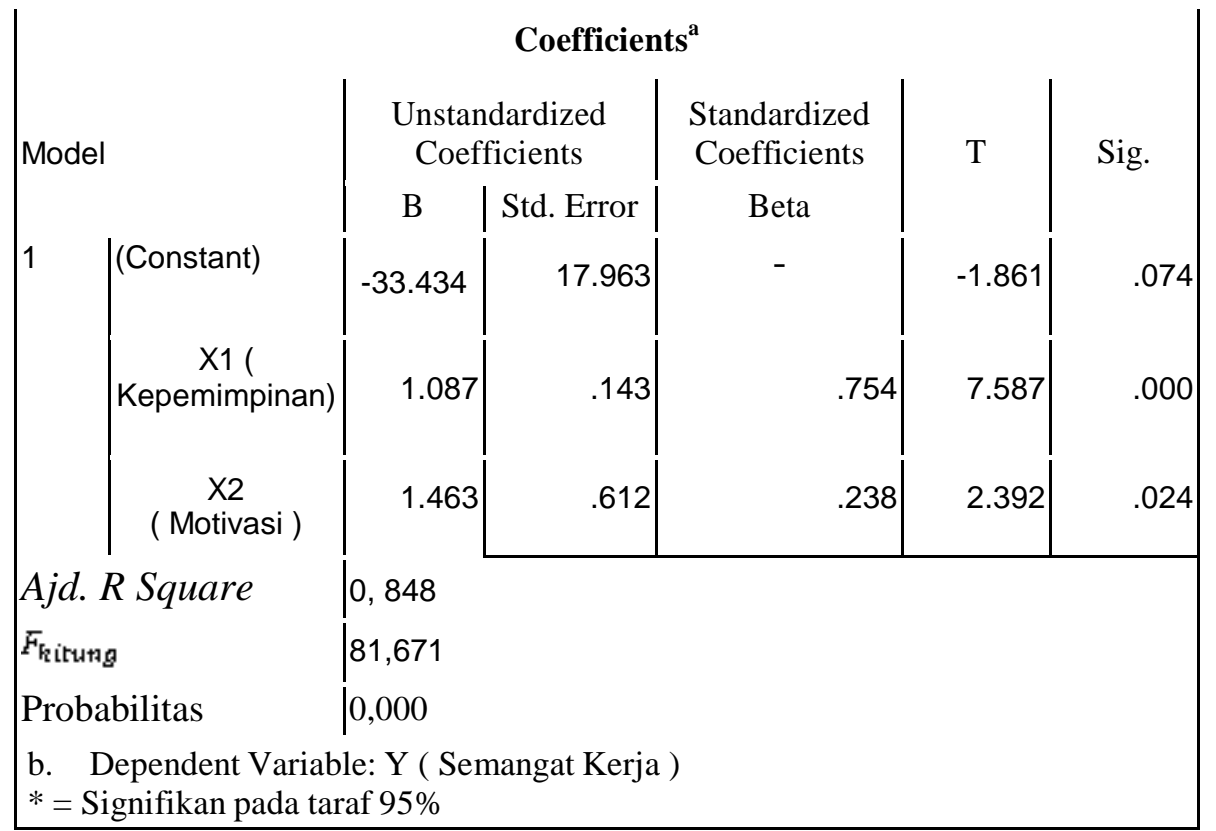

Sumber : Data di olah berdasarkan kuesioner yang di edarkan tahun 2015

Nilai koefisien regresi (B) adalah besar pengaruh masing-masing variabel independen (Kepemimpinan, dan Motivasi ) terhadap semangat kerja pegawai. Berdasarkan nilai koefisien regresi diatas dapat diketahui bahwa variabel Kepemimpinan (B) sebesar (0,502), dan variabel Motivasi (B) sebesar $(0,593)$ berpengaruh secara signifikan terhadap kinerja pegawai. Berdasarkan hasil analisis regresi maka dapat di rumuskan sebagai berikut : $\mathrm{Y}=$ $5.583+0,502 \mathrm{X} 1+0,593 \times 2+$. Besar pengaruh kepemimpinan, dan motivasi kerja secara simultan terhadap Semangat kerja pegawai ditunjukkan oleh besarnya nilai Adjusted R Square sebesar 0,848 Seperti pada tabel Adjusted R Square. Dibawa ini

Tabel 4. 13 Adjusted R Square kepemimpinan dan motivasi

\begin{tabular}{|c|c|c|c|c|}
\hline \multicolumn{5}{|c|}{ Model Summary ${ }^{b}$} \\
\hline Model & $\mathrm{R}$ & R Square & Adjusted R Square & $\begin{array}{l}\text { Std. Error of the } \\
\text { Estimate }\end{array}$ \\
\hline 1 & $.926^{\mathrm{a}}$ & .858 & .848 & .752 \\
\hline \multicolumn{5}{|c|}{ a. Predictors: (Constant), X2, X1 } \\
\hline \multicolumn{5}{|c|}{ b. Dependent Variable: Y } \\
\hline
\end{tabular}


Hal ini berarti Kepemimpinan, dan motivasi secara signifikan memberikan pengaruh sebesar 84,8 \% terhadap semangat kerja pegawai, sedangkan sisanya sebesar $15,42 \%$. dipengaruhi variabel lain yang tidak termasuk dalam penelitian ini.

\section{PEMBAHASAN}

Berdasarkan hasil analisis regresi secara parsial pada variabel Kepemimpinan di peroleh di peroleh nilai $t_{\text {hitung }}$ sebesar 4,677 dengan signifikan (p) 0,000 dan beta koefisien standardized sebesar 0,502. Maka hasil analisis ini menunjukkan bahwa Kepemimpinan secara parsial memiliki pengaruh yang signifikan dalam meningkatkan semangat kerja pegawai. Melalui hasil perhitungan yang telah dilakukan diperoleh nilai signifikan sebesar 0.000 dengan beta koefisien standardized sebesar 0,502, yang berarti bahwa hipotesis dalam penelitian ini menolak H0 dan menerima Ha. Maka dapat di jelaskan bahwa pengujian kepemimpinan secara parsial mempunyai pengaruh signifikan terhadap Semangat kerja Pegawai, hasil uji hipotesis secara parsial menunjukan bahwa Kepemimpinan berpengaruh secara signifikan terhadap Semangat kerja Pegawai, dimana $\mathrm{t}_{\text {hitung }}>\mathrm{t}$ tabel" yaitu (4.677 $\left.\geq 2.048\right)$ dengan tingkat signifikan $(0.000<$ 0.05). dengan demikian kriteria penolakan HO dapat dipenuhi, ini berarti HO ditolak. Sehingga dapat disimpulkan bahwa Kepemimpinan $\left(\mathrm{X}_{1}\right)$ berpengaruh signifikan terhadap Semangat Kerja Pegawai (Y) Pada Perusahaan Daerah Air Minum (PDAM) Kelurahan Saumlaki, Kabupaten Maluku Tenggara Barat

Berdasarkan hasil analisis regresi secara parsial pada variable Motivasi kerja di peroleh nilai $t_{\text {hitung }}$ sebesar 5,412dengan tingkat signifikan (p) 0,000 dan beta koefisien standardized sebesar 0,593. Maka hasil analisis ini menunjukkan bahwa Motivasi secara parsial memiliki pengaruh yang signifikan dalam meningkatkan Semangat kerja pegawai. melalui hasil perhitungan yang telah dilakukan diperoleh nilai signifikan sebesar 0.000 dengan beta koefisien standardized sebesar 0,593 , yang berarti bahwa hipotesis dalam penelitian ini menerima Ha dan menolak HO. Dari hasil uji hipotesis secara parsial menunjukan 
bahwa Motivasi $\left(\mathrm{X}_{2}\right)$ berpengaruh secara signifikan terhadap Semangat kerja Pegawai (Y), dimana $\mathrm{t}$ hitung $>\mathrm{t}$ tabel" yaitu $(5,412 \geq 2,048)$ dengan tingkat signifikan $(0.000<0.05)$. dengan demikian kriteria penolakan HO dapat dipenuhi, ini berarti H0 ditolak. Sehingga dapat disimpulkan bahwa Motivasi $\left(\mathrm{X}_{2}\right)$ berpengaruh signifikan terhadap Semangat kerja Pegawai (Y) Pada Perusahaan Daerah Air Minum (PDAM) Kelurahan Saumlaki, Kabupaten Maluku Tenggara Barat..

Dalam pengujian koefisien determinasi (R2), tingkat pengaruh vareiabel independen (Kepemimpinan dan motivasi) terhadap Semangat kerja Pegawai sebesar 77,6\% hal ini berarti bahwa Kepemimpinan dan motivasi kerja mempengaruhi Semangat Kerja Pegawai sebesar $84,8 \%$ sisanya $15,2 \%$ dipengaruhi oleh variabel lain diluar dari variabel yang digunakan.

Apabila dilihat dari tingkat signifikan, variabel independen (Kepemimpinan dan Motivasi Kerja,) secara simultan mempunyai pengaruh yang signifikan terhadap Kinerja Pegawai (F sebesar 81,671 $\geq 3.354$ ) dengan tingkat signiifikaan $0.000<0,05)$. Artinya Ho ditolak dan Ha di terima. Begitu pulah Jika nilai $\mathrm{F}_{\text {hitung }}>\mathrm{F}_{\text {tabel }}$ maka hipotesis Ho ditolak dan hipotesis alternatif Ha diterima, tetapi jika $F_{\text {hitung }} F_{\text {tabel }}$ maka hipotesis Ho diterima dan hipotesis alternatif $\mathrm{Ha}$ ditolak. Sehingga dapat di simpulkan bahwa Kepemimpinan dan motivasi kerja secara bersama sama dapat mempengaruhi Semangat Kerja Pegawai sebesar $84,8 \%$. Dengan demikian maka hipotesis Ha yang menyatakan bahwa terdapat pengaruh antara variabel Kepemimpinan (X1) dan motivasi (X2) terhadap Semangat Kerja Pegawai (Y) dapat diterima. Dengan demikian dapat disimpulkan bahwa Kepemimpinan (X1), Motivasi kerja (X2) berpengaruh terhadap Semangat kerja Pegawai (Y) Pada Perusahaan Daerah Air Minum (PDAM) Kelurahan Saumlaki, Kabupaten Maluku Tenggara Barat.

\section{DAFTAR PUSTAKA}

Ghozali, Imam. 2006. Aplikasi Analisis Multivariate Dengan Program SPSS. Semarang: Badan Penerbit Universitas Diponegoro. 
Mangkunegara, A. A, Anwar Prabu, 2009, Evaluasi Kinerja Sumber Daya Manusia, Refika Aditama, Bandung.

Mangkunegara, A. A, Anwar Prabu, 2011. Manajemen Sumber Daya Manusia Perusahaan, Remaja Rosdakarya, Bandung

Maslow, Abraham H., 1984, kepuasan kerjadan Kepribadian, Seri Manajemen No. 104 Cetakan Pertama PT. Pustaka Binaman Pressindo, Jakarta

Mangkunegara, Anwar Prabu. 2000. Manajemen Sumber Daya Manusia Perusahaan. Bandung : PT. RemajaRosdaKarya

Sastroadiwiryo.siswanto bejo, 2003, Manajemen Tenaga Kerja Indonesia, edisi 2, PT. Bumi Aksara

Ghozali, Imam. 2006. Aplikasi Analisis Multivariate Dengan Program SPSS. Semarang: Badan Penerbit Universitas Diponegoro

Ghozali, Imam. 2001. Aplikasi Analisis dengan Program SPSS. Undip: Semarang.

Hasibuan H.Malayu S.P., Drs. (2002).Managemen Sumber daya Manusia, PT.Bumi Aksara

Marthis R.L. dan Jackson J.H. 2002, Manajemen Sumber Daya Manusia, Salemba Empat, Jakarta. 